\title{
Sustainable Product-Service System Design applied to Distributed Renewable Energy

\author{
Fostering the goal of sustainable energy for all
}

\author{
Carlo Vezzoli ${ }^{1}$, Fabrizio Ceschin ${ }^{2}$, Jan Carel Dieh/ ${ }^{3}$ \\ ${ }^{1}$ Politecnico di Milano, Design Department, Design and system Innovation for Sustainability (DIS), \\ Milan, Italy carlo.vezzoli@polimi.it \\ ${ }^{2}$ Brunel University London, College of Engineering, Design and Physical Sciences, Department of \\ Design, Uxbridge, United Kingdom, fabrizio.ceschin@brunel.ac.uk \\ ${ }^{3}$ Delft University of Technology, Faculty of Industrial Design Engineering, Design for Sustainability, \\ Delft, The Netherlands, j.c.diehl@tudelft.nl
}

\begin{abstract}
Energy is a fundamental imperative to the quest for sustainable development. The current challenge is to provide sustainable energy solutions for all, while concomitantly increasing the access to energy and improving usage efficiency. Within this perspective, education in design in Higher Education Institutions (HEIs) must increasingly equip design students with a broad knowledge base, as well as effective methods and tools so that new generations of designers (and design educators) can play more effective roles in the development and diffusion of sustainable energy systems. This is the ambition of the Learning Network on Sustainable Energy Systems (LeNSes) project - an African-European multi-polar network for curricula development on Sustainable ProductService System (S.PSS) design applied to Distributed Renewable Energy (DRE). The research hypothesis of the LeNSes project is that S.PSS can be effectively applied to DRE, representing a promising opportunity to obtain synergies among the economic, environmental, and socio-ethical dimensions.
\end{abstract}

Keywords: Higher Education Institutions; Curriculum Development; Sustainable Product-Service Systems; Distributed Renewable Energy; Learning Resources; Open Source and Copyleft.

\section{Introduction}

This note from the field presents the theoretical background, the initial actions and the expected outcomes of the Learning Network on Sustainable Energy Systems (LeNSes) project - an AfricanEuropean multi-polar network for curricula development on Sustainable Product-Service System (S.PSS) Design applied to Distributed Renewable Energy (DRE). The project is funded by the European Union (EU) (2013-2016, Edulink Programme) and involves four African and three European universities ${ }^{1}$ offering design-specific programmes of study.

\section{Applying Product-Service System to Distributed Renewable Energy}

Equitable and reliable access to energy services is a fundamental imperative in the quest for sustainable societal development. It has a direct influence on the social, environmental and economic aspects of development. Access to energy services is a fundamental element for achieving national and regional developmental goals. Consequently, none of the Millennium Development Goals (MDGs) can be achieved without substantial improvements in the quality and quantity of

\footnotetext{
${ }^{1}$ Cape Peninsula University of Technology, University of Botswana, University of Nairobi, Makerere University, Politecnico di Milano, Brunel University and Delft University of Technology.
} 
energy services in emerging and low-income contexts. Thus, the challenge is to provide sustainable energy solutions for all, through increasing equitable access to energy services and improving usage efficiency.

In relation to this, it is promising to look at two interwoven models: the Sustainable Product-Service System (S.PSS) and the Distributed Renewable Energy system (DRE) initiatives:

- Distributed Renewable Energy systems (DREs) are small-scale generation plants sourced by renewable energy (such as sun, wind, water, biomass and geothermal energy), at or near the point of use, where the users are also the producers, whether individuals, small businesses and/or local communities. Additionally, nearby generator's systems can be connected into local small grids, to synergistically share their energy surpluses. By design, DREs promote the use of locally-based-distributed and eventually network-structured - renewable energy systems to obtain economic and environmental advantages, due to their reduced global warming impacts, inexhaustibility and lower environmental costs compared to extraction and use of fossil fuels. Moreover, DRE technologies are easy to install and manage by smallscale economic entities such as individuals and/or local communities, which empowers them and to no longer only be consumers but also producers of energy. Consequently, the widespread implementation of DREs can result in an extensive redistribution of power towards individuals and local communities, which is necessary to establish conditions for truly equitable sustainable societal development.

- Fortunately, Distributed Renewable Energies systems (DREs) are being increasingly documented as vital catalysts for achieving universal and equitable access to energy services and to society-wide social and economic development by ensuring universal education, healthcare and sustainable agriculture, by creating green jobs and by promoting equity throughout society (Colombo et al. 2013). In other terms, widespread implementation of DRE in low and middle-income contexts represents a paradigm shift needed in the energy sector at the global level (Sustainable Energy for All 2011; Vezzoli, 2010;Rifkin, 2011).

- Sustainable Product-Service System (S.PSS) is a model designed to help to provide an integrated mix of products and services that help to fulfill particular customer's needs, thereby delivering "units of satisfaction". It is based on innovative interactions among the stakeholders of the value production system (satisfaction system), where the economic and competitive interest of the providers continuously seeks both environmentally and socioethically beneficial new solutions (Vezzoli et al. 2014). S.PSSs are known offer models, potentially delinking resources consumption from its traditional connection with profit (Goedkoop et al. 1999; Mont, 2002). If properly conceived and implemented, S.PSSs can provide low-income communities equitable access to energy services that traditional product sales models do not provide.

\section{The Learning Network on Sustainable energy systems (LeNSes) project}

The research hypothesis of the LeNSes project is that S.PSS can be effectively applied to DRE, thereby providing promising opportunities to simultaneously achieve the following types of benefits: a. Economic through reduced initial investment costs, increased reliability and consequently reduced costs to consumers; b. Environmental due to increased efficiency, reduced emissions, thereby improving environmental security, and c. Socio-ethical benefits due to equitable (democratisation of) access to energy services, increased participation and independence of local people, and enhanced sense of 'control' over their own destiny.

Within this perspective, Higher Education Institutions (HEIs), which are engaged in educating design students, must provide them with a broad knowledge base, as well as effective methods and tools so that new generations of designers (and design educators) can play increasingly active roles in the 
development and widespread implementation of sustainable energy systems. These are the visions and intentions of the LeNSes project. In particular, the project aims to:

- Developing a shared knowledge-base and know-how on S.PSS and DRE, with a particular focus on design (i.e. thereby establishing the foundation for new roles for design of PSS systems for, equitable and sustainable energy for all);

- Building new design curricula based on this more systemic and integrative knowledge-base and know-how;

- Delivering these curricula through an innovative teaching approach based on an open and copyleft ethos, supported by an appropriate web platform for the decentralised production, transfer and use of learning resources.

In order to achieve these goals, the LeNSes project has been structured around the following six main activities:

1. State of the art. The first phase is aimed at setting-up the basis of the project. Each partner gathers and shares knowledge from previous didactic and research experiences in the field of locally based System Design for Sustainable Energy for all, and African partners will identify and discuss specific needs and priorities. In this process, the involvement of local companies, associations and NGOs is anticipated.

2. Design and implementation of didactic pilot modules. This stage involves the development of the necessary inputs for implementation of the didactic pilot courses and teaching subsidies. Didactic pilot courses are designed and the necessary teaching subsidies are developed ex-novo, according to needs and demands. The design of the didactic modules is now in progress, in collaboration among African partners, European partners, with the support of the local associates (companies, consultancies and organisations operating in the energy sector). In the first round of the work, the pilot module's implementation will be done through an exchange modality: each African partner hosts a course, and is an observer in another course implemented by another African partner HEl. Each European partner collaborates in the implementation by acting as a guest school. In the second round, courses are integrated in the African partners' curricula, with long distance support by the European partners.

3. Design and implementation lifelong learning pilot modules. This stage addresses the development of the necessary inputs for the implementation of professional training modules for companies, consultancies and organisations. As a pilot case, each African partner, in collaboration with European partners, will develop and deliver professional training to the respective companies, consultancies and organisations of the host HEl.

4. Development of the Open Learning E-Platform (OLEP). ${ }^{2}$ In parallel with the didactic curricular and lifelong learning activities, the OLEP will be in design and development processes, to be then filled in with contents, i.e. learning resources such as slide shows, texts, audio, video, etc., and System Design for Sustainable Energy for All tools. The OLEP is designed to be an open online platform that actively supports decentralised and collaborative production, use and adaptation of knowledge to support didactic and lifelong learning activities in diverse cultural and physical contexts. During the project, the OLEP contents are made freely available in an open and copy left ethos (i.e. without copyright, with Creative Common licence) to any (African and European, and citizens of all other

\footnotetext{
${ }^{2}$ The LeNSes teaching approach and the OLEP are based on the result of the LeNS project (Vezzoli and Ceschin, 2011), a 3-year project (2007-2010) funded by EU under the Asia Link Programme.
} 
countries, worldwide) HEI teacher, student and practitioner. Since this is an open package, it is planned that the project will continue to be updated after the end of the project.

5. Dissemination. The results of implementation of both the didactic curricular courses and the lifelong learning modules and their supporting learning resources and tools will be collected to be used in a number of dissemination activities. The main ones will be: an international conference, a workshop with representatives from African HEls, a book on System Design for Sustainable Energy for All, and a set of guidelines to support HEls in implementing didactic courses and lifelong learning activities. Most importantly, the central contribution of the OLEP is to facilitate adoption, adaptation and development of the project results by HEls, regionally and globally.

The LeNSes project has currently entered the second year. African partners' specific needs and priorities have been gathered and analysed and are being used to design the syllabi of the first four didactic pilot courses. LeNSes partners are in the process of collecting/developing the learning resources to be used in those courses. In parallel, the web platform that will host the resources is being developed. The design requirements have been established and a beta version has been released (www.lenses.polimi.it). The first pilot course on "System Design for Sustainable Energy for All (SD4SEA)" was implemented in October 2014 in Cape Town, South Africa. The videos and slides of all the lectures, as well as all the design tools used, are now available and free to download in copy left from the website lenses.polimi.it in the section COURSES and TOOLS. The courses covers the following subjects ${ }^{3}$ : Sustainable Energy for All; Sustainable Product-Service System (S.PSS) Design; System design for Sustainable Energy for All; Distributed Renewable Energy (DRE) systems; Human centered design for Distributed Renewable Energy (DRE) products; Life Cycle Design of Distributed Renewable Energy (DRE) generators; Economy, financing and regulatory sustainable energy for all.

\section{Expected outcomes}

The project will contribute to the development of new knowledge on S.PSS design applied to DRE in the context of low-income settings as well as to the development of an educational platform to support the diffusion, adoption and adaptation of the new knowledge.

In particular, in terms of contribution to knowledge the expected outcomes are:

- $\quad$ An in depth understanding of S.PSS applied to DREs, in terms of: 1, characteristics, 2. environmental, socio-ethical and economic benefits, 3 . drivers and barriers and 4 . classification of existing models.

- A set of new approaches and tools to support designers and practitioners in designing sustainable energy systems for all.

- A collection of case studies of S.PSS applied to DREs in low-income settings.

Regarding the diffusion of the new knowledge and know-how, the main expected output is the Open Learning E-Platform (OLEP). This will support the decentralised production and transfer of knowledge and know-how in the area of locally based system designs for sustainable energy for all, through:

- A modular and adaptable e-package comprised of teaching/training materials and teaching tools and guidelines for courses/modules design and implementation in diverse contexts;

\footnotetext{
${ }^{3}$ Professors and researchers from the Design and Mechanical Engineering department of the CPUT (Mugendi M'Rithaa, Andrea Broom, Sven Pietrangeli, Omar llyas and Fareed Ismail), from the Design department of Politecnico di Milano University (Carlo Vezzoli and Emanuela Delfino), and from the Design department of the University of Botswana (Paulson Letsholo).
} 
- A set of free tools to support the design of sustainable energy systems;

- $\quad$ Long-distance co-education web tools, to support collaboration among: African HEls; African HEls and European HEls; and African HEls and local socio-economic actors, with a particular focus upon practitioners, companies, consultancies and organisations active in the renewable energy services sector);

- A repository of best practices/concepts/ideas on sustainable energy systems, with a special focus upon S.PSS and DRE.

\section{References}

Colombo, E., Bologna, S., Masera D. (eds.) (2013) Renewable Energy for Unleashing Sustainable Development, DOI: 10.1007/978-3-319-00284-2_1, Springer International Publishing Switzerland.

Goedkoop, M.J., van Halen, C.J.G., te Riele, H.R.M. and Rommens, P.J.M. (1999) Product Service Systems, Ecological and Economic Basis, PricewaterhouseCoopers N.V./Pi!MC, Storrm C.S., Pre consultants.

Mont O (2002) Drivers and Barriers for Shifting Towards more Service-Oriented Businesses: Analysis of the PSS field and contribution from Sweden. Journal of Sustainable Product Design 2: 89-103.

Rifkin J. (2011) The Third Industrial Revolution. How Lateral Power is Transforming Energy, the Economy, and the World. New York: Palgrave Macmillan.

Sustainable Energy for All (2011) Sustainable Energy for All, A Vision Statement by Ban Ki-moon, United Nations Secretary-General. Available at http://www.sustainableenergyforall.org/resources.

Vezzoli, C. (2010) System design for sustainability. Theory, methods and tools for a sustainable "satisfaction-system" design, Rimini, Maggioli Editore.

Vezzoli, C., and Ceschin, F. (2011) The Learning Network on Sustainability: an e-mechanism for the development and diffusion of teaching materials and tools on Design for Sustainability in an opensource and copy left ethos. International Journal of Management in Education 5(1): 22-43.

Vezzoli C., Kohtala C., Srinivasan A., with Xin L., Fusukal M., Sateesh D. and Diehl J.C. (2014) Product Service System Design for Sustainability, Sheffield, UK: Greenleaf Publishing.

Worldwatch Institute (2012) State of the World 2012: Moving Toward Sustainable Prosperity. Washington USA: Worldwatch Institute. 